Full citation: Matthews, T. and Baker, D. (2109) 'Advancing responses to climate change through improved interplay between planning theory and practice' International Planning Studies.

DOI: $10.1080 / 13563475.2019 .1674640$

\title{
Advancing responses to climate change through improved interplay between planning theory and practice
}

\author{
Authors \\ Dr Tony MATTHEWS (Corresponding Author) \\ School of Environment \& Science, Griffith University, Nathan Campus, 170 Kessels Road, \\ Nathan, QLD 4111, Australia. Email: t.matthews@ griffith.edu.au

\section{Professor Douglas BAKER} \\ School of Civil Engineering and Built Environment, Queensland University of Technology, 2 \\ George Street, Brisbane, QLD 4001, Australia. Email: d2baker@qut.edu.au
}

\begin{abstract}
Climate change is challenging planning agencies worldwide and the need to respond is becoming unavoidable. This paper proposes a central task for contemporary planning theory is to guide practice as it responds. It focuses on the Western Anglophone world and argues that the achieving a successful interplay between theory and practice lies in clearly translating theoretical constructs into the domain of real-world planning practice. Friedmann's tasks for planning theory are employed as a framework to assess the potential of planning theories to guide climate change response through practice. Associated issues discussed include the influence of translatable planning theories in shaping planning practice, as well as the value of importing knowledge from other disciplines. Three theoretical constructs - anticipatory governance, legitimacy and socialecological resilience - are then examined in terms of their capacity to provide theoretically informed options to planning practice. The paper concludes that a more engaged and reciprocal conversation between planning theory and practice could improve planning responses to the climate change threat. This should enable planning theory to translate its conceptual discoveries to the world of planning practice, whilst simultaneously refining its insights based on rigorous analyses of practice contexts, processes, dilemmas, capacities and limitations.
\end{abstract}

\section{Keywords}

Climate change, planning theory, planning practice

\section{Introduction}

An essential task for planning theory is to consider the conditions necessary to produce better places and to address how these may be met through the interplay of theory and practice (Fainstein, 2005). We argue that contemporary planning theory has not adequately envisioned ways for planning practice to respond to the profound real-world challenges associated with climate change. The paper argues a crucial role for substantive planning theory, based in realist ontology, is to articulate the challenges that climate change places in the domain of planning practice now and into the future. Climate change will be a driver of change in human settlements for the foreseeable future (IPCC, 2014). Planning practice in the Western Anglophone world, which this paper focuses on, is increasingly required to respond to related, serious changes in urban management, land use and spatial development (Biesbrock, Swart \& van der Knapp, 2009; Jabareen, 2013; Matthews, 2013). Efforts to respond through planning practice have so far advanced largely in the absence of substantive theoretical guidance. Instead, they have been largely driven by perceptions of risk connected to experiences of climate-related, fast-onset traumas like extreme floods or droughts (Brody et al., 2008; Hamin, 2011; Matthews, 2014). 
Full citation: Matthews, T. and Baker, D. (2109) 'Advancing responses to climate change through improved interplay between planning theory and practice' International Planning Studies.

DOI: $10.1080 / 13563475.2019 .1674640$

We argue in this paper that universality of climate change and its potentially catastrophic impacts requires that articulation of the concept be brought into contemporary planning theory. We see a crucial role for substantive planning theory in responding to the real-world challenges climate change places in the domain of planners, now and into the future. We call for planning theory to focus on realist ontology, rather than the anti-realist turn it took in recent years, which diminished its capacity to guide planning practice (Allmendinger, 2002; Harrison, 2014; March, 2010). We utilise Friedmann's (2008) three tasks for planning theory as a mechanism for appraising the capacity of theoretical constructs to meaningfully guide planning practice. We discuss how each task - philosophy, adaptation and translation - provides a basis for substantively articulating different aspects of climate change and translating that knowledge into the domain of planning practice. We then interrogate the potential utility of three theoretical constructs to meet these aims - anticipatory governance, legitimacy and social-ecological resilience. We discuss related matters, including the influence of translatable planning theories in shaping planning practice, communicating theoretical discoveries to practitioners and the value of importing knowledge from other disciplines. We also provide a response to critiques of the potential and efficacy of Friedmann's framework. We conclude that a more engaged and reciprocal conversation between planning theory and practice could improve planning responses to the climate change threat in the Western Anglophone world. This should enable planning theory to translate its conceptual discoveries to the real-world domain of planning practice, whilst simultaneously refining its insights based on rigorous analyses of practice examples, contexts, processes, dilemmas, capacities and limitations.

\section{Responses to climate change from planning practice}

Climate change is now a dominant process of ongoing global change (Heinrichs, Krellenberg \& Fragkias, 2013). It is projected to generate a range of impacts into the future, which will vary in incidence and intensity (IPCC, 2014; UN-HABITAT, 2011). Overall global temperatures are projected to increase, leading to changes to rainfall patterns, increased frequency and severity of extreme weather events and droughts, as well as an increased probability of heatwaves. Coastal flooding and inundation will increase due to rising sea levels and more frequent inland storm surges. Approximately $70 \%$ of global greenhouse gas emissions are generated in the world's urban areas (UN-HABITAT, 2011). Cities contribute substantially to climate change and their viability and function is likely to be impacted over the coming centuries. The nature and scope of potential climate change impacts means that the majority of cities worldwide, with concentrated populations facing threats from escalating urban heat and disruption linked to extreme weather events. The population concentration in cities makes them especially vulnerable, but less populous settlements, including those located in peri-urban, regional, rural and remote areas, are also vulnerable.

Planning practice is "a set of governance practices for developing and implementing strategies, plans, policies and projects and for regulating the location, timing and form of development" (Healey et al. 1999, p. 31). Planning practice occurs across scales of government and within the private sector. Planning practice involves many portfolios, including social and community planning, environmental planning, natural resource management, transport planning and infrastructure planning (Binder and Boldero, 2012). Planning practice involves advisors and decision-makers who interact to create a planning agency (Faludi, 1973). Planning agencies then engage in the act of planning; that is, they bring "scientific advice to bear on decisions concerning policies during an interactive process involving the roles of advisors and decision-makers" (Faludi, 1973, p. 2). 
Full citation: Matthews, T. and Baker, D. (2109) 'Advancing responses to climate change through improved interplay between planning theory and practice' International Planning Studies.

DOI: $10.1080 / 13563475.2019 .1674640$

Contemporary planning may now be understood as taking place in an over-arching context of climate change (Steele and Gleeson, 2009). The new reality requires planning to have "both a short term focus and long term strategic thinking in order to develop the collective action around education, mitigation and adaptation required at multi-scalar governance levels" (Steele and Gleeson, 2009, p. 9). Many urban planning agencies globally are now moving towards agenda where climate change response is understood as necessary and unavoidable, rather than a future or abstract challenge (Hamin, 2011). Responses by planning practice can focus on mitigation or adaptation, or a combination of both (Biesbrock, Swart \& van der Knapp, 2009; Wilson, 2006). Mitigation involves directly or indirectly lowering greenhouse gas emissions, while adaptation involves direct action to minimize and manage predicted negative consequences of climate change, or creating strategies to accrue benefit from any positive impacts (IPCC, 2014). Planning practice is a strategic public policy area in many countries, meaning that many planning agencies are potentially well positioned to anticipate, prepare for and manage adverse spatial impacts associated with climate change (Wilson, 2006). Institutional planning responses to climate change may occur through spatial and land-use policies and regulations, strategic stakeholder engagement and capacity building (Gleeson, 2008; Jabareen, 2013; Hamin \& Gurran, 2009; Matthews, 2013). Technical responses can include plan making, development management, urban design and zoning, all of which are near universal tools for planning practice (Gleeson, 2008; Hamin \& Gurran, 2009).

Planning practice can respond to climate change though mitigation in two principal ways. The first approach involves increasing densities of built stock in urban areas (Hamin \& Gurran, 2009; Shaw, Colley \& Connell, 2007). This approach holds that high densities can reduce greenhouse gas emissions by reducing land use requirements and consolidating the delivery of services and utilities. Residential, employment, retail and other services can be planned to exist in closer proximity, potentially reducing emissions as people need to travel less for common activities like grocery shopping and commuting to and from work (Shaw, Colley \& Connell, 2007). The second approach focuses on improving public transport provision in existing areas and in tandem with efforts to increase densities. Cities with dense form tend to use less transport energy per capita on aggregate (Creutzig, Mühlhoff \& Römer, 2012; Rickwood, Glazebrook \& Searle, 2008). Quality public transport is especially useful in lowering car dependence, which acts as a form of mitigation by minimising congestion, land clearing for road provision and gas emissions from vehicles (Rickwood, Glazebrook \& Searle, 2008).

Planning agencies wishing to respond to climate change through adaptation may be able increase the adaptive capacity of both new and existing urban developments (Gleeson, 2008; Matthews, 2013; Newman, Beatley \& Boyer, 2009). For example, planning can use existing technical tools like development assessment, remote sensing and design standards to direct the use of climate sensitive design and materials and green infrastructure. These technologies can help to cool urban spaces, limit urban heat island effect, better manage stormwater run-off associated with intense rainfall events and attenuate flood impacts. Planning practice may also use plan making as a means to coordinate the preparation of bespoke, location-specific adaptation plans focused on delivering targeted and locally-appropriate adaptive interventions (Matthews, 2013).

Development management processes can direct new development and re-development in specific ways to ensure that spatial, land-use and infrastructural interventions have in-built adaptive capacity. Planning agencies may also have potential to build adaptive responses directly into urban development plans and planning schemes, along with specific implementation and monitoring strategies (Matthews, 2013; Newman, Beatley \& Boyer 2009).

\section{Responses to climate change from planning theory}


Full citation: Matthews, T. and Baker, D. (2109) 'Advancing responses to climate change through improved interplay between planning theory and practice' International Planning Studies.

DOI: $10.1080 / 13563475.2019 .1674640$

The challenge for planning theory is to conceptually engage with the conditions necessary to create better places and to examine how these can be delivered through the interplay of theory and practice (Fainstein, 2005). Planning theory in therefore embodies a requirement to describe planning goals and conceptualise means for attaining those goals. Specific planning theories come in many forms, each with their own intellectual underpinnings, peculiarities, contributions and problems (Binder, 2011). Planning theories are important to scholars and practitioners, as the work of planning research and practice is shaped by intuition derived from assimilated theoretical knowledge (Campbell \& Fainstein, 1996; McKay, Murray and MacIntyre, 2015). For the purposes of this paper, we consider planning theory to include theoretical content from planning scholarship and associated disciplines that offers utility to planning practice in meeting the challenge of conceptually depicting and practically creating better places.

We share concerns about recent drifts in planning theory away from meaningfully engaging with spatial realities. Scholarly discussions on the value of contemporary planning theory have debated its tendency towards an anti-realist ontology, which "has largely replaced a focus on epistemology with a concern for hermeneutics" (Harrison, 2014, p. 66). This ontological paradigm is anchored in postmodernist thinking and focuses on interpreting spatial realities via power structures, rather than envisioning substantive directions for practice. This 'anti-realist turn' has severely diminished the capacity of much recent planning theory to guide practice (Allmendinger, 2002; Beauregard, 1990; March, 2010; Yiftachel, 1999; Sanyal, 2002). The resulting intellectual disconnect creates a situation where "much of planning theory discusses what planners do with little reference either to the socio-spatial constraints under which they do it or the object they seek to affect" (Fainstein, 2005, p. 121).

The anti-realist turn has agitated some scholars, who see it as harmful to the planning imagination (Allmendinger, 2002; Beauregard, 1990; Yiftachel, 1999). Harrison (2014) observes that "the worth of the planning theory project arguably rests on its ability to enhance planning practice in the 'real world' and it is here that planning theory still struggles to make the connections" (p. 68). If planning practice is understood as orientated towards improving spatial outcomes and creating better communities, then planning theory should inform, guide, and help planning practitioners in seeking and affecting positive change (March, 2010). This suggests that conceptual engagement with the spectrum of factors, issues and challenges that condition space should be central to planning theory. We argue that this rationale is particularly relevant in a climate change context.

Scholars have argued that planning responses to climate change are not generally driven by theoretical rationales; instead they are driven by perceptions of risk and recent experiences of climate-related, fast-onset traumas like extreme floods or droughts (Brody et al., 2008; Hamin, 2011; Matthews, 2014). The complexity and uncertainty of climate change as an emerging urban challenge provides context for planning theory to articulate the phenomenon within the planning imagination (Campbell, 2012; Matthews, 2013). Contemporary planning theory has started to acknowledge this necessity, but engagement is limited so far. The most notable socio-spatial insight translated from theory to practice to date is the idea that increased densities can reduce emissions and are therefore useful for mitigating climate change (Creutzig, Mühlhoff \& Römer, 2012; Hamin \& Gurran, 2009; Rickwood, Glazebrook \& Searle, 2008).

\section{Responses to climate change from an interplay of planning and practice}

Contemporary planning theories have a role in envisioning and articulating the challenges climate change places in the domain of urban planning practice, yet this remains at an early stage (Binder, 
Full citation: Matthews, T. and Baker, D. (2109) 'Advancing responses to climate change through improved interplay between planning theory and practice' International Planning Studies.

DOI: $10.1080 / 13563475.2019 .1674640$

2011; Brody et al., 2008; Hamin, 2011; Matthews, 2014). Many of the nuances associated with the task are yet to be explored, particularly in terms of their capacity to be translated into guidance for planning practice. We contend that contemporary planning theory has a critical role in guiding planning practice in its efforts to respond to climate change. We see significant value in planning theories providing translatable knowledge to assist planning practice as it responds to climate change now and into the future. Challenges may be spatial, ethical, social, political or economic. Planning theories may inform practice by identifying and interrogating emerging challenges connected to climate change and conceptually appraising potential responses. Responses may require new or altered forms of planning governance, language and ethics.

We utilise Friedmann's (2008) three tasks for planning theory - philosophy, adaptation and translation - to assess the potential of planning theories to guide climate change response through practice. As Friedmann asserts, the utility of the framework lies in its capacity to highlight "three ways that theorising in and about planning contributes to our professional field" (2008, p. 248). The philosophical task is based on a humanist approach that is needed because "as planners we do not have a well thought-out philosophical position beyond the usual platitudes of participation" (Friedmann, 2008, p. 248). This first task is the source of much of the planning theory literature in the areas of power (Forester, 1989; Flyvberg, 2002), collaboration (Brand \& Gaffikin, 2007; Agger and Lofgren, 2008) social learning (Innes and Booher, 2015; Inch, 2015) and ethics (Hendler, 1995; Campbell, 2006). The second task of adaptation is also a common theme in planning literature. The changing nature of how we plan and the dynamic substantive elements of planning require adaptation to changing knowledge and context. Adaptation is a common theme in literature, with adaptive management as one of the premises in effective resource and environmental planning (Berkes and Ross, 2013; Skrimizea, Haniotou, and Parra, 2019). Translation is also a common theme in planning theory that acknowledges the diversity of knowledge and the trans-disciplinary character of planning (Bolan, 2017; Rydin, 2007). Each of these themes will be expanded upon as follows.

\section{Philosophy}

The philosophical task for planning theory is to evolve value-based philosophies to inform and guide practice. Contemporary planning practice is understood as value-laden. This creates a necessity for philosophical foundations to guide planners. These philosophies can support planners in efforts to guide spatial development in ways that foster social and environmental justice. Friedmann argues the growing recognition that planning practice is value-laden has allowed it to evolve beyond being a technocratic process. Contemporary planning practice is moving towards a participative and inclusive process that tries to engage with stakeholders to achieve consensus (Brand \& Gaffikin, 2007; Quick \& Feldman, 2011). Friedmann criticises this approach as unsuited to an increasingly materialist, individualistic world that is largely indifferent to anthropogenic environmental impacts. Consequently, relying too heavily on the value of consensus from stakeholders with limited social or environmental concern means that planning practice may inadvertently contribute to spatial outcomes that are ecologically and socially unsustainable. Following Friedmann's logic, responses to climate change through planning practice appear unlikely to generate meaningful action if planners are beholden to the pursuit of consensus for its own sake. Stakeholder engagement can lead to consensus and the possibility of transformative outcomes, though excessive consultation risks undermining the authority of planners and their expertise (Forrester, 1999).

Stakeholder engagement and the pursuit of consensus are likely to remain important within a context of climate change (Reis et al., 2013). We suggest activating planning theory to guide 
Full citation: Matthews, T. and Baker, D. (2109) 'Advancing responses to climate change through improved interplay between planning theory and practice' International Planning Studies.

practice should include a philosophical acceptance of the social and environmental interdependence of human communities. We see value in theoretical constructs that provide a moral foundation to articulate the interdependence of human communities and their interrelationship with climate change. Planners may benefit from the articulation of clear, value-based philosophies, advanced through theory and cognizant of the value-laden interconnection between climate change and planning practice. Such an approach may allow planners to proceed with climate change response secure in the knowledge that planning interventions can have a valid role. This could lead the way towards a paradigm where planning practice still values engagement and consensus, but fully recognizes that planners themselves offer important expertise that is highly relevant to decision-making. The advancement of value-based philosophies through contemporary planning theories links closely to issues of establishing legitimacy in practice-led climate change response, as well as flexible decision-making strategies present in anticipatory governance.

New professional philosophies may give planners the confidence to engage with stakeholders in order to achieve actionable outcomes that are focused on long-term community betterment rather than short-term stakeholder placation. This philosophical shift may allow planners to set an agenda of climate change response that seeks but is not always beholden to stakeholder input. This may be especially useful in situations where consensus is not achievable because of emergencies or immediate imperatives created by climate change impacts. Contemporary planning theory may ultimately be able to help shape a context for spatial development that is much more ecologically and socially sustainable by focusing more closely on Friedmann's task of philosophy. Within this context, it will require a focus on providing value-based philosophies capable of guiding planning practice in delivering legitimate practice responses to climate change through both mitigation and adaptation. While we call for planning theory to advance value-based philosophies that distinctly position climate change response within contemporary planning practice, we also acknowledge that responding to climate change cannot be value-free.

\section{Adaptation}

The second of Friedmann's three tasks for planning theory is adaptation. Friedmann identifies the major adaptations within planning theory that have informed practice over the past half century as "dialogue, social learning, mutual learning, social participation, collaboration, mediation, social mobilization, social and political empowerment, and strategic planning or visioning" (2008, p. 254). The need for planning to adapt is depicted as a function of larger social, economic, cultural and environmental processes that intersect with planning in shifting ways. Friedmann characterises planners as professionals with cognitive limitations who work within planning agencies that are territorially and administratively bounded. Within this context, planning practice tries, but doesn't always succeed, in linking knowledge to action in an effort to guide spatial outcomes that are socially just and inclusive (Campbell, 2006). However, the reliability of knowledge as a basis for planning decisions can be uncertain, particularly when decision-making in the present seeks to provide a suitable basis for future circumstances (Tangney \& Howes, 2016). Friedmann regards this approach as problematic because some contemporary variables that are germane to decision-making may be under-represented, while potential future variables may be completely ignored. Moreover, the selection of variables can often be biased, as planners rely on their training and education to provide guidance.

Applying Friedmann's logic to planning theory guiding planning practice in climate change response suggests that the reliability of contemporary knowledge as a basis for planning decisions with future implications may be problematic. For example, complex models are used to chart 
Full citation: Matthews, T. and Baker, D. (2109) 'Advancing responses to climate change through improved interplay between planning theory and practice' International Planning Studies.

potential future impacts of climate change. Planners can use these projections as a basis for developing responses through mitigation or adaptation. However, the reliability of climate change models may be challenged and planners and stakeholders may question their validity (Tangney \& Howes, 2016). Moreover, planners may struggle to understand how projected impacts will affect their specific cities and what policy responses are appropriate (Webb, 2017). This may cause planners to interpret and engage with uncertain variables when attempting to formulate response to climate change. Planners may return to their training and education to find ways of navigating such dilemmas. However, it is possible that this may be of limited assistance given that many planners working today likely have limited training in integrating climate change response into planning processes.

The major adaptations within planning theory identified by Friedmann are connected to larger social, economic, cultural and environmental processes that intersect with planning. The environmental, social, economic and cultural processes linked to climate change are likely to intersect with planning now and into the future. Climate change provides a new set of urgent circumstances that are likely to require further adaptations within planning. We suggest that the nature and character of these adaptations can be envisioned and debated by planning theory and the knowledge created through this process can be utilised by practice. Climate change impacts may ultimately shape planning more than they are shaped by it. We suggest that planning theory seeking to guide practice should be mindful of this reality and attentive to the speed and nature of spatial changes linked to climate change.

We propose planning theory should focus heavily on developing visions of how to adapt to climate change institutionally, strategically, ethically and linguistically. The scale and extent of the climate change threat means that contemporary and future planning practice will encounter new and unanticipated challenges. These may include issues like community relocation, i.e. 'climigration', (Bronen and Chapin, 2013; Matthews \& Potts, 2018), planned retreat from coastlines (Niven \& Bardsley, 2013) or negative effects on human health caused by urban heat islands (Rinner \& Hussain, 2011). Planning practice may face great difficulty in pursuing spatial outcomes that are socially just when faced with disruptive and sometimes sudden impacts. As such, we see an opportunity for planning theory to guide these adaptations by recognising and articulating the challenges that climate change places in the domain of planners now and into the future.

\section{Translation}

Friedmann's third task for planning theory is translation. Planning theory is inter-disciplinary, insomuch as it imports knowledge from allied disciplines. Friedmann argues that the wide scope of spatial dynamics means that many planning issues are often best understood through an interdisciplinary lens. This is underscored by considering the many specializations that feature within planning, including but not limited to "transportation, public health, housing, urban design [and] community development" (Friedmann, 2008, p. 254). Friedmann cautions that dismissing potential contributions from other disciplines risks intellectual stasis within the planning imagination. As such, the task of translation relates to an ongoing developmental journey for planning theory. This involves planning theorists actively seeking out new concepts and ideas that can be translated to and implemented through planning practice.

We see a connection between Steele and Gleeson's (2009) perspective that contemporary planning is taking place in a context of climate change and Friedmann's task of translation. Climate change response is likely to become a new and crucial specialization within planning 
Full citation: Matthews, T. and Baker, D. (2109) 'Advancing responses to climate change through improved interplay between planning theory and practice' International Planning Studies.

DOI: $10.1080 / 13563475.2019 .1674640$

(Matthews, 2013). The urgency of this agenda may be hastened by escalating spatial impacts over time. An opportunity exists for contemporary planning theory to look to other disciplines for translatable knowledge. As previously discussed, planning practice responses to climate change up to now have largely occurred in the absence of substantive theoretical guidance (Brody et al., 2008; Hamin, 2011; Matthews, 2014). We believe that guidance from planning theory can benefit from knowledge imported from other disciplines. In doing so, planning theory may generate theoretical discoveries that can be translated into the language of planning and employed to guide climate change response through practice.

We highlight four allied disciplines where planning theory may find translatable knowledge, though we acknowledge that there are likely many more. The first is disaster management. Climate change impacts like sea level rise and increased flooding are likely to severely impact on coastal urban communities (Song et al., 2018), potentially to a point where planned relocation known as 'climigration' - becomes unavoidable (Matthews and Potts, 2018). Contemporary planning practice has limited knowledge of multiple facets and implications of such responses. Experiential knowledge translated from the discipline of disaster management via planning theory may therefore be valuable. The second is psychology. The social psychology of communities that are severely affected by extreme weather or displaced by disaster may be profoundly harmed (Doherty \& Clayton, 2011; Reser and Swim, 2011). Engaging with residents and stakeholders from these communities may require extreme sensitivity. Psychology may be able to guide planners in how to approach such situations. It may also be able to provide ethical guidance for instances where planners are required to separate personal feelings from professional decisionmaking in emotive situations.

The third allied discipline is political science. Planners may struggle to advocate for climate change response if they feel they lack the capacity to engage with and mediate between the political sphere and the scientific community (Tangney \& Howes, 2016). Knowledge from political science may offer translatable knowledge. Planners may be able to draw upon this in their efforts to generate scientific and political support for new policy frameworks and governance arrangements designed to deliver climate change response. The fourth allied discipline of potential use is communication studies. Current and future impacts connected to climate change may have wide implications that need to be framed, discussed and communicated to various actors (Nerlich, Koteyko and Brown, 2010). Impacts may extend to private property and development rights, as well as existing and future spatial circumstances. Translated knowledge from communication studies via planning theory may help planning practice in effectively communicating with stakeholders in instances where private property and development rights are affected by climate change impacts.

\section{Discussion}

Climate change is a phenomenon with profound implications for planning and planners. As such, we see strong value in planning theories that provide knowledge but also direct planning practice in harnessing this knowledge. Friedmann's three tasks for planning theory provide a useful framework for assessing the potential of planning theories to guide climate change response through practice. We acknowledge there are critiques of the potential and efficacy of Friedmann's model, which may provide a basis for critiquing the suggestions we make in this paper. Binder, for example, criticises Friedmann's model because it emphasizes "the role of the individual while leaving the nature of normativity and the role of the state under-theorized [and] propose[s] that the 'solution' is to instill the 'right' (i.e. the proponents') values." (2011, p. 227). Applied to the this paper, if planning theory tries to guide climate change response through practice, it risks 
Full citation: Matthews, T. and Baker, D. (2109) 'Advancing responses to climate change through improved interplay between planning theory and practice' International Planning Studies.

DOI: $10.1080 / 13563475.2019 .1674640$

over-estimating the capacity of planners to capitalise on the opportunities it brings, while also implying that any proposed solution is problematic because it is value-laden. We reject these arguments on the basis that they underestimate the capacity of planners to want to improve planning practice and to actively work towards better outcomes, even within challenging power structures. Moreover, we earlier noted that responses to climate change from planning practice have so far occurred largely in the absence of substantive theoretical guidance (Brody et al., 2008; Hamin, 2011; Matthews, 2014). This could potentially continue indefinitely were planning scholars and practitioners to reject any and all solutions on the basis that they were not value neutral. As such, we regard avoiding action entirely on the basis that responses may be valueladen as unreasonable and unworkable.

We now turn our attention to interrogating three theoretical constructs - anticipatory governance, legitimacy and social-ecological resilience - in terms of the potential of each to conceptually and practically articulate the challenges climate change places in the domain of planners. We consider each relative to Friedmann's three tasks. We focus on these theoretical examples because they appear to offer real-world potential to practice, based on evidence and cases documented in scholarly literature. While we focus on these three theoretical constructs, we acknowledge that there may be others in this realm.

Anticipatory governance is a conceptual decision-making framework that can translate particular knowledge to build increased capacities in foresight, engagement and integration (Barben et al., 2008; Guston, 2013). These capacities support scientists, policy makers and other public actors to reflect on their own positions as participants within a larger field of actors (Guston, 2013).

Anticipatory governance may offer a theoretical basis to guide planning practice as it responds to changing impacts of climate change (Boyd et al., 2015; Quay, 2010). It can allow planners to explore uncertainty and make decisions based on a feedback loop of assessment and monitoring. It is a scenario-based approach designed to guide planning processes in adapting to climate change impacts as they happen. As Fuerth (2009, p. 29) notes, anticipatory governance offers "a way to use foresight for the purpose of reducing risk, and to increase capacity to respond to events at early rather than later stages of their development''. Anticipatory governance offers significant potential for developing strategies under uncertain environmental futures because it allows multiple strategies to be anticipated across different temporal scales, while considering a range of possible futures (Boyd et al., 2015). This flexibility aligns it with Friedmann's task of adaptation. The complexities, uncertainties and future horizons associated with climate change mean that traditional predict-and-plan approaches may be insufficient for deciding on the nature and character of social and capital investments. Anticipatory governance may overcome these challenges by offering a more flexible decision-making context for planners in the face of the high levels of uncertainty and long range futures associated with climate change. In other words, the approach supports the development of new value-based philosophies. It also aligns with Friedmann's task of adaptation, as it was translated from natural resource/ecology literature into planning (Quay, 2010). Evidence from planning practice in Denver, New York City and the City of Phoenix provides indications of the potential for successful interplay between theory and practice related to anticipatory governance. Planners in each case are using the theoretical construct to develop innovative new approaches to climate change response through planning practice and yielding positive outcomes (Quay, 2010).

Theoretical considerations of the concept of legitimacy may also offer potential to better guide responses to climate change through planning practice (Klein, Mantysalo \& Juhiola, 2015; Mees \& Driessen, 2018). Legitimacy to respond to climate change through planning practice is a critical conditioning factor that can facilitate or hinder responses (Klein, Mantysalo \& Juhiola, 
Full citation: Matthews, T. and Baker, D. (2109) 'Advancing responses to climate change through improved interplay between planning theory and practice' International Planning Studies.

2015). Different planning paradigms, including comprehensive-rationalist planning, incrementalism, communicative planning and agnostic planning, shape the character and nature of practice-led responses. Theoretical perspectives hold that legitimacy is critical in order for practice to respond to climate change, irrespective of which planning paradigm it occurs in (Klein, Mantysalo \& Juhiola, 2015). New institutional settings designed to deliver adaptive responses may have increased potential for success and greater levels of legitimacy when linked to other planning goals (Mees \& Driessen, 2018). An illustrative example may be a citywide green infrastructure scheme, delivering more trees, shade and parklands. A planning-led initiative like this may enjoy greater legitimacy amongst planners and stakeholders because green infrastructure use not only lowers air temperature and energy demand, but also provides increased capacity for urban biodiversity and increased aesthetic value. To further improve possibilities for success, planners could, for example, link the green infrastructure scheme to another planning intervention with existing legitimacy, such as urban consolidation and densification goals. However, it is important to distinguish between policy arrangements and implementation arrangements to more fully understand or measure legitimacy relative to interventions like this (Klijn and Koppenjan, 2012). Advancing theoretical notions of legitimacy through planning theory before translating them to planning practice in this style could potentially yield real-world benefit and would likely meet each of Friedmann's tasks.

Another theoretical approach focuses on the application of social-ecological resilience as a means for problem setting and solving within planning practice (Lloyd, Peel \& Duck, 2013; Wilkinson, 2012). This approach embraces systems ecology to explore theoretical approaches to deal with global scale change. The case for social-ecological resilience is made on the basis that the concept offers planning theory a guide to understand human-nature relations. It informs planners of how the social-ecological systems are linked and exists across nested levels. Social-ecological resilience may involve various scales of application and can encounter numerous feedbacks, drivers and nonlinearities, as well as unpredictability, disturbance events and windows of opportunity (Berkes \& Ross, 2012). Wilkinson argues that, "one specific area of interest for planning theory that emerges with respect to the way social-ecological resilience conceptualises the dynamics of change regards the role of surprise, sometimes also called disturbance, crisis or shock" (2012, p. 160). This is a valid conceptual point because climate change impacts are unlikely to occur in a linear or predictable fashion. Quickly formulated and implemented planning responses may be suddenly required in cases where severe climate change impacts suddenly occur. Professional philosophies and planning ethics may be heavily challenged during such times. It may also be critical to adapt practice protocols and translate knowledge from elsewhere. As such, the social-ecological construct accommodates Friedmann's theoretical tasks while offering a framework for planners to respond quickly and holistically to climate change impacts on the ground, whether they are rapid onset or not.

At this juncture we reflect on four further relevant questions for consideration. The first concerns whether planning practice really needs input from planning theory as it attempts to formulate and implement responses to climate change. If recent planning practice proceeded with climate change responses largely in the absence of theoretical input, then is there really a need for theoretical input? We strongly believe that there is a need for substantive theory to support practice in its efforts towards an agenda of response. We see a crucial role for planning theory in visioning and conceptualising possible urban futures so that practice has a set of roadmaps to work from. Climate change impacts are unpredictable. Cumulative and single extreme events may radically alter spatial realities. We suggest that planning theory can once more embrace visioning, as it has throughout its history, to imagine possible spatial futures and the implications of these for practice. 
Full citation: Matthews, T. and Baker, D. (2109) 'Advancing responses to climate change through improved interplay between planning theory and practice' International Planning Studies.

DOI: $10.1080 / 13563475.2019 .1674640$

The second question is how and when can new theoretical visions for climate change response be communicated to planners? We suggest that opportunities exist at two points. The first is during the education of new planners. Many university planning courses now educate emerging planners on the interplay between planning and climate change. The necessity of teaching this in planning education will likely increase over time, especially as climate change impacts intensify and agreements like the Paris Agreement of 2015 place climate change response firmly in the domain of planners. The second is through continuing professional development opportunities for qualified planners. Planning is not static and the education of planners tends to be ongoing, albeit in a reduced way, throughout their careers. Some of the spatial challenges associated with climate change may exceed the lived experience of many urban planners. As such, we believe there is constant scope for translating new theoretical constructs to assist planning practitioners in responding to climate change.

Another important question is whether planning in the Western Anglophone world can do anything other than the will of capital in an era of neo-liberalism? Scholars have noted the steady encroachment of neoliberal ideals into all facets of planning. The focus of planning within a neoliberal framework orientates toward economic development, giving primacy to market forces and making urban areas economically competitive (Waterhout, Othengrafen, \& Sykes, 2013). Reforms aimed at changing the objectives of planning tend to contextually reflect neoliberal ideals (Olesen, 2014; Waterhout, Othengrafen \& Sykes, 2013). The capacity of planning to adequately respond to climate change in a neoliberal context may be limited, or perhaps even absent, unless it can be explicitly depicted as economically advantageous. We acknowledge this conundrum and suggest that the contemporary planning theory should consider this realpolitik in its efforts to conceptually inform planning practice in the Western Anglophone world where neoliberal ideals are dominant.

The fourth question is whether planning can ever seriously mitigate carbon emissions, considering the timeframes for response and the slow rates of built environment change? Whilst we consider planning-led mitigation to be important, we accept there are limitations. Built environments are very slow to change, buildings and infrastructure typically designed to last 50 to 150 years (Biesbrock, Swart \& van der Knapp, 2009). Efforts to achieve planning-led mitigation through consolidated urban form are therefore more likely to be of use in future developments. Moreover, the idea of higher densities improving mitigation outcomes may not always hold. Higher density developments may in fact be more energy intensive than dispersed settlements (Clark, 2013; Gray, Gleeson \& Burke, 2010). There is also evidence that planning has a weak influence on travel behaviour even when it prioritises consolidated urban forms (Headicar, 2009). Climate change mitigation through manipulation of the built environment may therefore exceed the scope of meaningful planning response (Gleeson, 2008; Matthews, 2013). This is why many scholars now argue an urgent necessity for planning to focus on adaptation as a superior climate change response (cf. Bulkeley and Kern, 2006; Gleeson 2008; Matthews, 2013; Newman, Beatley and Boyer, 2009). As such, we suggest that conversations between planning theory and practice, designed to improve planning responses to climate change, should focus more on adaptation, while not entirely excluding mitigation.

\section{Conclusion}

This paper argued that planning theory has not yet fully engaged with the phenomenon of climate change as a unique and urgent urban planning challenge. In response, we proposed that a central task for realist planning theory is to guide practice as it responds to climate change. Practice-led 
Full citation: Matthews, T. and Baker, D. (2109) 'Advancing responses to climate change through improved interplay between planning theory and practice' International Planning Studies.

DOI: $10.1080 / 13563475.2019 .1674640$

responses to climate change have so far evolved largely without theoretical guidance. We see this as an impetus for theoretical development where planning theories articulate the real world challenges that climate change places in the domain of planners. We conclude that a more engaged and reciprocal conversation between planning theory and practice could improve planning responses to the climate change threat in the Western Anglophone world. This should enable planning theory to translate its conceptual discoveries to the domain of planning practice, whilst simultaneously refining its insights based on rigorous analyses of practice contexts, processes, dilemmas, capacity and limitations.

As a concluding comment, we encourage further dialogue on the capacity of planning theory to guide planning practice in responding to climate change in the Western Anglophone world. Our intention for this paper is to add further perspective and knowledge to this dialogue. We actively invite and support other voices to join the conversation. The perspectives offered in this paper represent a small fraction of the intellectual content the conversation requires. We welcome further contributions in the knowledge that our collective potential for success can be amplified by contributions from scholarly and practicing colleagues. Climate change may prove to be the greatest spatial challenge faced by humanity. If so, we believe hope for successful response lies in a more engaged and reciprocal conversation between planning theory and practice. This should enable planning theory to translate its conceptual discoveries to the real world domain of practice. Simultaneously, it can refine its insights based on rigorous analyses of practice contexts, processes, dilemmas, capacity and limitations. This reciprocal relationship may become key to shaping better futures for human settlements in the era of climate change.

\section{References}

Agger, A. \& Lofgren, K. (2008) Democratic assessment of collaborative planning processes. Planning Theory, 7 (2), pp.145-164. doi: 10.1177/1473095208090432.

Allmendinger, P. (2002) Towards a post-positivist typology of planning theory. Planning Theory, 1(1), 77-99. doi: 10.1177/147309520200100105

Barben, D., Fisher, E., Selin, C. and Guston, D.H. (2008) Anticipatory governance of nanotechnology: Foresight, engagement, and integration. In: Hackett, E.J., Amsterdamska, O., Lynch, M. and Wajcman, J. (eds) The Handbook of Science and Technology Studies. Cambridge, MA: The MIT Press, pp. 979-1000.

Beauregard, R. (1990) Bringing the city back in. Journal of the American Planning Association, 56(2), 210-215. doi: 10.1080/01944369008975760

Berkes, F. and Ross, H. (2013) Community resilience: Toward an integrated approach. Society \& Natural Resources, 26(1), 5-20. doi: 10.1080/08941920.2012.736605

Biesbroek, G.R., Swart, R.J. \& van der Knaap, W.G.M. (2009) The mitigation-adaptation dichotomy and the role of spatial planning. Habitat International, 33(3), 230-237. doi:10.1016/j.habitatint.2008.10.001

Binder, G. (2011) Theory(izing) practice: The model of recursive practical adaptation. Planning Theory, 11(3), 221-241. doi: 10.1177/1473095211433570

Binder, G. and Boldero, J. M. (2012) Planning for change: The roles of habitual practice and habitus in planning practice. Urban Policy and Research, 30(2), 175-188. doi: 10.1080/08111146.2012.672059

Bolan, R. (2017) Urban planning's philosophical entanglements: The rugged, dialectiocal path from knowledge to action. New York. Routledge. ISBN: 9781138233591

Boyd, E., Nykvist, B., Borgström, S., Stacewicz, I.A. (2015) Anticipatory governance for socialecological resilience. AMBIO, 44(1), 149-161. doi: 10.1007/s13280-014-0604-x

Brand, R. and Gaffikin, F. (2007) Collaborative planning in an uncollaborative world. Planning 
Full citation: Matthews, T. and Baker, D. (2109) 'Advancing responses to climate change through improved interplay between planning theory and practice' International Planning Studies.

DOI: $10.1080 / 13563475.2019 .1674640$

Theory, 6(3), 282-213. doi: 10.1177/1473095207082036

Brody, S.D., Zahran, S., Grover, H. \& Vedlitz, A. (2008) A spatial analysis of local climate change policy in the United States: Risk, stress and opportunity. Landscape and Urban Planning, 87(1), 33-41. doi:10.1016/j.landurbplan.2008.04.003

Bronen, R. and Chapin, F.S. (2013) Adaptive governance and institutional strategies for climateinduced community relocations in Alaska. Proceedings of the National Academy of Sciences. 110(23): 9320-9325. doi: 10.1073/pnas.1210508110

Bulkeley, H. and Kern, K. (2006) Local government and the governing of climate change in Germany and the UK. Urban Studies 43(12): 2237-2259. doi: 10.1080/00420980600936491

Campbell, H. (2006) Just planning: the art of situated ethical judgement. Journal of Planning Education and Research, 26, 92-106. doi: 10.1177/0739456X06288090:

Campbell, H. (2012) Planning to change the world: Between knowledge and action lies synthesis. Journal of Planning Education and Research, 32(2), 135-146. doi: 10.1177/0739456X11436347

Campbell, S. and Fainstein, S. (1996) (Eds) Readings in planning theory. Cambridge, MA: Blackwell Publishers.

Clark, T. A. (2013) Metropolitan density, energy efficiency and carbon emissions: Multi-attribute trade-offs and their policy implications. Energy Policy, 53, 413-428,

Doherty, T.J. and Clayton, S. (2011) The psychological impacts of climate change. American Psychologist, 66(4), 265-276. doi: 10.1037/a0023141

Fainstein, S. (2005) Planning theory and the city. Journal of Planning Education and Research, 25, 121-130. doi: 10.1177/0739456X05279275

Faludi, A. (1973) What is planning theory? In: Faludi, A. (Ed) A reader in planning theory (pp. 110). Oxford: Pergamon Press.

Forester, J. (1989) Planning in the face of power. Berkeley: University of California Press. ISBN: 0520063104

Friedmann, J. (2008) The uses of planning theory: A bibliographic essay. Journal of Planning Education and Research, 28(2), 247-257. doi: 10.1177/0739456X08325220

Fuerth, L.S. (2009) Foresight and anticipatory governance. Foresight, 11, 14-32.s. $10.1108 / 14636680910982412$

Gleeson, B. (2008) Waking from the dream: An Australian perspective on urban resilience. Urban Studies, 45(13), 2653-2668. doi: 10.1177/0042098008098198

Gray, R., Gleeson, B. and Burke, M. (2010) 'Urban Consolidation, Household Greenhouse Emissions and the Role of Planning,' in Urban Policy and Research 28(3), 335-346. doi: $10.1080 / 08111146.2010 .490618$

Guston, D.H. (2014) Understanding 'anticipatory governance'. Social Studies of Science. 44(2), 218-242. doi: $10.1177 / 0306312713508669$

Hamin, E.M. (2011) Integrating adaptation and mitigation in local climate change planning. In: G.K. Ingram and H. Yu-Hung (Eds) Climate Change and Land Policies (pp. 122-143). Cambridge, Massachusetts: Lincoln Institute of Land Policy.

Hamin, E.M. \& Gurran, N. (2009) Urban form and climate change: Balancing adaptation and mitigation in the U.S. and Australia. Habitat International, 33(3), 238-245. doi:10.1016/j.habitatint.2008.10.005

Harrison P (2014) Making planning theory real. Planning Theory, 13(1), 65-81. doi: $10.1177 / 1473095213484144$

Headicar, P. (2009) Transport policy and planning in Great Britain. Abingdon: Routledge.

Hendler, S. (1995) Planning ethics: a reader in planning theory practice and education. New Brunswick N.J.: Centre for Urban Policy Research. ISBN: 0882851519

Healey, P., Khakee, A., Motte, A. and Needham, B. (1999) European developments in strategic spatial planning. European Planning Studies, 7(3), 339-355. 
Full citation: Matthews, T. and Baker, D. (2109) 'Advancing responses to climate change through improved interplay between planning theory and practice' International Planning Studies.

DOI: $10.1080 / 13563475.2019 .1674640$

Heinrichs, D., Krellenberg, K. \& Fragkias, M. (2013) Urban responses to climate change: Theories and governance practice in cities of the global south. International Journal of Urban and Regional Research, 37(6), 1865-1878. doi: 10.1111/1468-2427.12031

Inch, A. (2015) Ordinary citizens and the political cultures of planning: In search of the subject of a new democratic ethos. Planning Theory, 14 (4), 404-424. doi: 10.1177/1473095214536172

Innes, J. and Booher, D. (2015) A turning point for planning theory? Overcoming dividing discourses. Planning Theory, 14 (2), 195-213. doi:10.1177/1473095213519356

IPCC (2014) Summary for Policymakers. In V.R. Barros, C.B. Field, D.J. Dokken, M.D. Mastrandrea, K.J. Mach, T.E. Bilir, M. Chatterjee, K.L. Ebi, Y.O. Estrada, R.C. Genova, B. Girma, E.S. Kissel, A.N. Levy, S. MacCracken, P.R. Mastrandrea, L.L. White (Eds) Climate Change 2014: Impacts, adaptation, and vulnerability. Contribution of Working Group II to the Fifth Assessment Report of the Intergovernmental Panel on Climate Change (pp. 1-32). Cambridge: Cambridge University Press.

Jabareen, Y. (2013) Planning for countering climate change: Lessons from the recent plan of New York City. International Planning Studies, 18(2), 221-242. doi: 10.1080/13563475.2013.774149

Klein, J., Mantysalo, R. \& Juhola, S. (2015) Legitimacy of urban climate change adaptation: a case in Helsinki. Regional Environmental Change, 16(6), 815-826. doi: 10.1007/s10113-0150797-y

Klijn, E.H., and Koppenjan, J.F.M. (2012) Governance Network Theory: Past, Present and Future. Policy and Politics, 40(4), 187-206. doi: 10.1332/030557312X655431

Lloyd, M.G., Peel, D. and Duck, R.W. (2013) Towards a social-ecological resilience framework for coastal planning. Land Use Policy, 30(1), 925-933. Doi: 0.1016/j.landusepol.2012.06.012

McKay, S., Murray, M., \& MacIntyre, S. (2015) Pitfalls in Protection: How Theory can enrich our understandings of regulatory compliance problems in planning practice. International Planning Studies, 20 (3), 270-291. doi: 10.1080/135634.75.2014.985196

March, A. (2010) Practising theory: when theory affects urban planning. Planning Theory, 9(2), 108-125. doi: 10.1177/1473095209357864

Matthews, T. (2013) Institutional perspectives on operationalising climate adaptation through planning. Planning Theory and Practice, 14(2), 198-210. doi: 10.1080/14649357.2013.781208

Matthews, T. (2014) Storylines of institutional responses to climate change as a transformative stressor: the case of regional planning in South East Queensland, Australia. Environment and Planning C, 33(5), 1092-1107. doi:10.1068/c13206

Matthews, T. and Potts, R. (2018) Planning for climigration: a framework for effective action. Climatic Change, 148(4), 607-621. doi: 10.1007/s10584-018-2205-3

Nerlich, B., Koteyko, N. and Brown, B. (2010) Theory and language of climate change communication. WIREs Climate Change, 1, 97-110. doi: 10.1002/wcc.2

Newman, P., Beatley, T. \& Boyer, H. (2009) Resilient cities: Responding to peak oil and climate change. London: Island Press.

Niven, R. and Bardsley, D. (2013) Planned retreat as a management response to coastal risk: a case study from the Fleurieu Peninsula, South Australia. Regional Environmental Change 13(1): 193-209. doi: 10.1007/s10113-012-0315-4

Olesen, K. (2014) The neoliberalisation of strategic spatial planning. Planning Theory, 13(3), 288-303. doi: 10.1177/1473095213499340

Quay, R. (2011) Anticipatory governance: A tool for climate change adaptation. Journal of the American Planning Association, 76(4), 496-511. doi: 10.1080/01944363.2010.508428

Quick, K.S. and Feldman, M.S. (2013) Distinguishing participation and inclusion. Journal of Planning Education and Research, 31(3), 272-290. doi: 10.1177/0739456X11410979 
Full citation: Matthews, T. and Baker, D. (2109) 'Advancing responses to climate change through improved interplay between planning theory and practice' International Planning Studies.

DOI: $10.1080 / 13563475.2019 .1674640$

Reis, K., Grant-Smith, D., Burton, P., Howes, M., Heazle, M., Tangney, P. \& Bosomworth, K. (2013) Re-conceptualizing community resilience in Australian disaster risk management. Proceedings of Climate Adaptation 2013 Conference, Sydney, 25-27 June, 2013.

Reser, J.P. and Swim, J.K. (2011) Adapting to and coping with the threat and impacts of climate change. American Psychologist, 66(4), 277-289. doi: 10.1037/a0023412

Rickwood, P., Glazebrook, G. \& Searle, G. (2008) Urban structure and energy: A review. Urban Policy and Research, 26(1), 57-81. doi: 10.1080/08111140701629886

Rinner, C. and Hussain, M. (2011) Toronto's Urban Heat Island-Exploring the Relationship between Land Use and Surface Temperature. Remote Sensing, 3(6), 1251-1265. doi: $10.3390 / \mathrm{rs} 3061251$

Rydin, Y. (2007) Re-Examining the Role of Knowledge within Planning Theory. Planning Theory, 6 (1), 52-68. doi: 10.1177/1473095207075161

Sanyal, B. (2002) Globalization, ethical compromise and planning theory. Planning Theory, 1(2), 116-123. doi: 10.1177/147309520200100202

Shaw, R., Colley, M. \& Connell, R. (2007) Climate change adaptation by design: a guide for sustainable communities. London: Town and Country Planning.

Skrimizea, E., Haniotou, H., \& Constanza, P. (2019) On the 'complexity turn' in planning: A adaptive rationale to navigate spaces and times of uncertainty. Planning Theory, 18 (1), 122142. doi: $10.1177 / 1473095218780515$

Song, J., Fu, X., Wang, R., Peng, Z., \& Gu, Z. (2018) Does planned retreat matter? Investigating land use change under the impacts of flooding induced by sea level rise. Mitigation and Adaptation Strategies for Global Change, 23(5), 703-733.

Steele, W. \& Gleeson, B. (2009) Planning In Climate Change: Towards a Relational Framework for Action. Research Paper 26. Brisbane: Urban Research Program.

UN-HABITAT (2011) Cities and Climate Change - Global Report on Human Settlements 2011. London: Earthscan.

Waterhout, B., Othengrafen, F., \& Sykes, O. (2013) Neo-liberalization processes and spatial planning in France, Germany, and the Netherlands: An exploration. Planning Practice \& Research, 28(1), 141-159. doi: 10.1080/02697459.2012.699261

Webb, B. (2017) The use of urban climatology in local climate change strategies: a comparative perspective. International Planning Studies, 22(2), 69-84. doi: 10.1080/13563475.2016.1169916

Wilkinson, C. (2012) Social-ecological resilience: Insights and issues for planning theory. Planning Theory, 11(2), 148-169. doi: 10.1177/1473095211426274

Wilson, E. (2006) Adapting to climate change at the local level: The spatial planning response. Local Environment: The International Journal of Justice and Sustainability, 11(6), 609-625. doi: 10.1080/13549830600853635

Yiftachel, O. (2006) Planning theory at a crossroad: The third Oxford conference. Journal of Planning Education and Research, 18, 267-270. doi: 10.1177/0739456X9901800308 